\title{
The Impact of Wearing a Face Mask during the COVID-19 Pandemic on Temporomandibular Joint: A Radiological and Questionnaire Assessment
}

\author{
Moath Zuhour $^{1}$ Majid Ismayilzade ${ }^{1}$ Mehmet Dadacl $^{1} \quad$ Bilsev Ince $^{1}$ \\ ${ }^{1}$ Department of Plastic Reconstructive and Aesthetic Surgery, Meram \\ Address for correspondence Moath Zuhour, MD, Department of \\ Faculty of Medicine, Necmettin Erbakan University, Konya, Turkey \\ Plastic and Reconstructive and Aesthetic Surgery, Meram Faculty of \\ Medicine, Necmettin Erbakan University, 42080 Meram, Konya, \\ Indian J Plast Surg 2022;55:58-65. \\ Turkey (e-mail: muazzuhour@gmail.com).
}

\begin{abstract}
Aim Several health problems have been reported to be triggered or facilitated by prolonged mask usage during the coronavirus disease 2019 (COVID-19) pandemic. While wearing a face mask, people tend to push their jaws forward and downward in a repetitive manner to hold their masks in the right position; these jaw motions may induce temporomandibular joint disorder (TMD). In this study, we aimed to investigate these repetitive jaw movements while wearing face masks and their effects on TMD. Patients and Methods Patients who applied with TMD signs between June 2020 and May 2021 were evaluated prospectively. A survey using a questionnaire was conducted to define patients with TMD that caused only by mask-related repetitive jaw movements. Demographic data (age and gender), mean duration of daily mask usage, mask type, and magnetic resonance imaging results were recorded.

Results Prolonged daily mask usage ( $\geq 8$ hours/day) was significantly higher in patients with mask-related habits (group a) with a rate of $40.4 \%(p \approx 0.001)$. Also, in this group, the disc displacement with reduction rate (54.6\%) was higher compared with other groups $(p \approx 0.010)$. On the contrary, patients with no underlying risk factor

Keywords

- COVID-19 pandemic

- face mask

- temporomandibular disorder

- Surgical mask (group $c)$ showed an unexpected high osteoarthritis rate $(p \approx 0.029)$.

Conclusions In this study, we demonstrate that correcting the position of a face mask by repetitive jaw movements can increase the occurrence of TMD. Informing individuals wearing face masks about the risk of TMD and the importance of choosing the appropriate mask size according to the face shape are important issues to be addressed in the near future.
\end{abstract}

\section{Introduction}

Although 40 to $70 \%$ of people have at least one of the temporomandibular joint disorder (TMD) symptoms, only one in four is aware and seeks treatment for this unfavorable condition. ${ }^{1,2}$ The etiology and pathogenesis of TMD are not fully understood, and the management of these disorders is still a matter of discussion. ${ }^{3}$ Although occlusal problems have been considered to be the main underlying mechanism of TMD for years, recent investigations have demonstrated the etiology to be multifactorial rather than mere occlusal. ${ }^{4,5}$ The fundamental principles of TMD management focus on published online

February 25, 2022
DOI https://doi.org/ $10.1055 / \mathrm{s}-0042-1743131$ ISSN $0970-0358$.

\footnotetext{
(c) 2022. Association of Plastic Surgeons of India. All rights reserved This is an open access article published by Thieme under the terms of the Creative Commons Attribution-NonDerivative-NonCommercial-License, permitting copying and reproduction so long as the original work is given appropriate credit. Contents may not be used for commercial purposes, or adapted, remixed, transformed or built upon. (https://creativecommons.org/ licenses/by-nc-nd/4.0/)

Thieme Medical and Scientific Publishers Pvt. Ltd., A-12, 2nd Floor, Sector 2, Noida-201301 UP, India
} 
the triggering or initiating factors that induce these disorders. ${ }^{3}$ Previous studies have emphasized the association between lifestyle habits like chewing gum, nail biting, and clenching teeth with TMD. ${ }^{6-9}$

Wearing a face mask is one of the several strict precautions that have been globally applied since the beginning of the coronavirus disease 2019 (COVID-19) pandemic. ${ }^{10} \mathrm{Al}-$ though it was rescinded in some countries, it is still mandatory in others like Turkey. Children under the age of 2 years, patients with breathing difficulties or disabilities were exempted from wearing face masks. ${ }^{11}$ Among various mask types, the surgical mask is the best to prevent droplet transmission of COVID $19 .{ }^{12}$ Regardless of types, a mask should cover both nose, mouth, and chin properly.

Several adverse effects have been reported due to prolonged face mask usage with dermatological conditions being the majority. ${ }^{13,14}$ The association between prolonged face mask usage and other adverse effects like anxiety, epilepsy, and ocular problems is still debatable. ${ }^{15-18}$ Depending on several factors like the dimensions of the face, the mask elasticity, and binding strength, face masks tend to go close or even over the lower eyelid during the daily usage. Such a position makes people feel uncomfortable; to correct it they push their jaws maximum forward (mandible protrusion) and then maximum downward (mandible rotation) to gain the desired position (-Fig. 1). We believe that these repetitive jaw motions can induce temporomandibular joint (TMJ) dysfunction. Herein, we investigate the association of repetitive jaw movements while wearing a face mask with TMD.

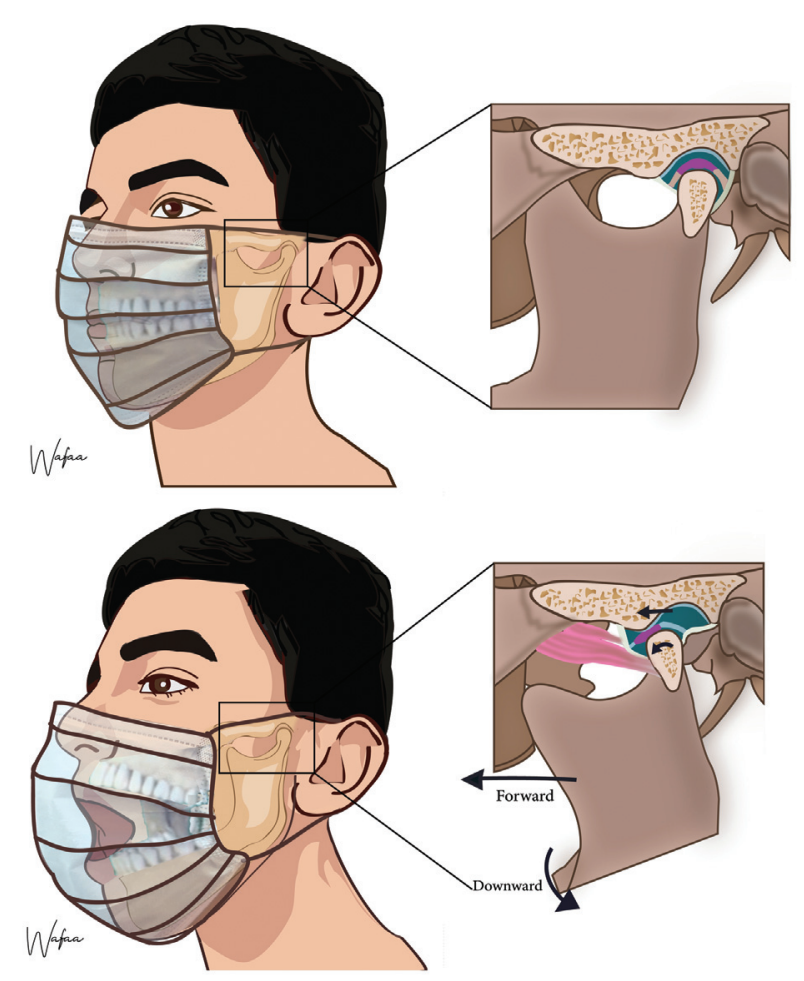

Fig. 1 Schematic illustration demonstrating the repetitive jaw movement used to get the face mask in appropriate position and its effects on temporomandibular disk (illustrations were made by Wafaa Z.).

\section{Patients and Methods}

This prospective study included the patients who applied to our plastic surgery clinic with TMD complaints (pain, articular noises, stiffness, joint lock, and joint tension) between June 2020 and May 2021. The patients with ongoing complaints before COVID-19, history of oro-dental surgical procedure, and comorbid diseases were excluded from the study (-Fig. 2).

Patients included in the study were subjected to a brief survey questionnaire on mask usage behaviors and lifestyle habits (-Fig. 3). The questionnaire consisted of two parts with nine questions regarding mask usage and lifestyle habits. The section of parafunctional habits was prepared according to the screening questionnaire recommended by the American Academy of Orofacial Pain. ${ }^{19,20}$ We used this questionnaire-which is usually used to determine the risky individuals with TMD-to separate the patients into three groups: group a included the patients who only had maskrelated repetitive movements as a risk factor, group b included the patients who also had lifestyle/parafunctional habits, and group c consisted of patients who did not have any known risk factor (-Fig. 2).

Demographic data (age and gender), mean duration of daily mask usage, and mask type were recorded. The patients using more than one type of masks were not included to get accurate standardization. To evaluate the effects of maskrelated repetitive jaw motions on TMJ, magnetic resonance imaging (MRI) was performed and evaluated by two different radiologists on the basis of blinded interpretations. Ethics committee approval was obtained. Both verbal and written informed consents were provided by patients in accordance with the principles of Helsinki Declaration.

Data were analyzed by SPSS statistical software version 24.0 , and quantitative variables were presented as mean \pm standard deviation. Chi-square test was applied. $p \leq 0.05$ was considered statistically significant.

\section{Results}

A total of 148 patients who presented with TMD were subjected to screening procedure; 42 of them were excluded as they had comorbid diseases, ongoing complaints for more than 1 year (before the COVID-19 pandemic), or a history of oro-dental surgery (-Fig. 2). The remaining 106 patients participated in the survey questionnaire. Mask-related repetitive jaw motions without any lifestyle/parafunctional habits were detected in 39 patients which constituted our study group (group a). Fifty-five patients with lifestyle habits were included in group $b$, while 12 patients with no known underlying cause were included in group $c$.

The mean age of group a was 31 years, $74 \pm 11.6$, while it was 34 years, $20 \pm 9.8$ in group b, and 35 years, $67 \pm 12.7$ in group c. The male-to-female ratio in groups was 11:28, 4:7, and $2: 1$. Prolonged daily mask usage ( $\geq 8$ hours/day) was $40.4 \%$ in group a compared with $15.3 \%$ in group c $(p=0.001)$. Low mask usage ( $\leq 3$ hours/day) was seen in $9.2 \%$ (lowest rate) of patients in group a $(p=0.028)$. In all groups, 


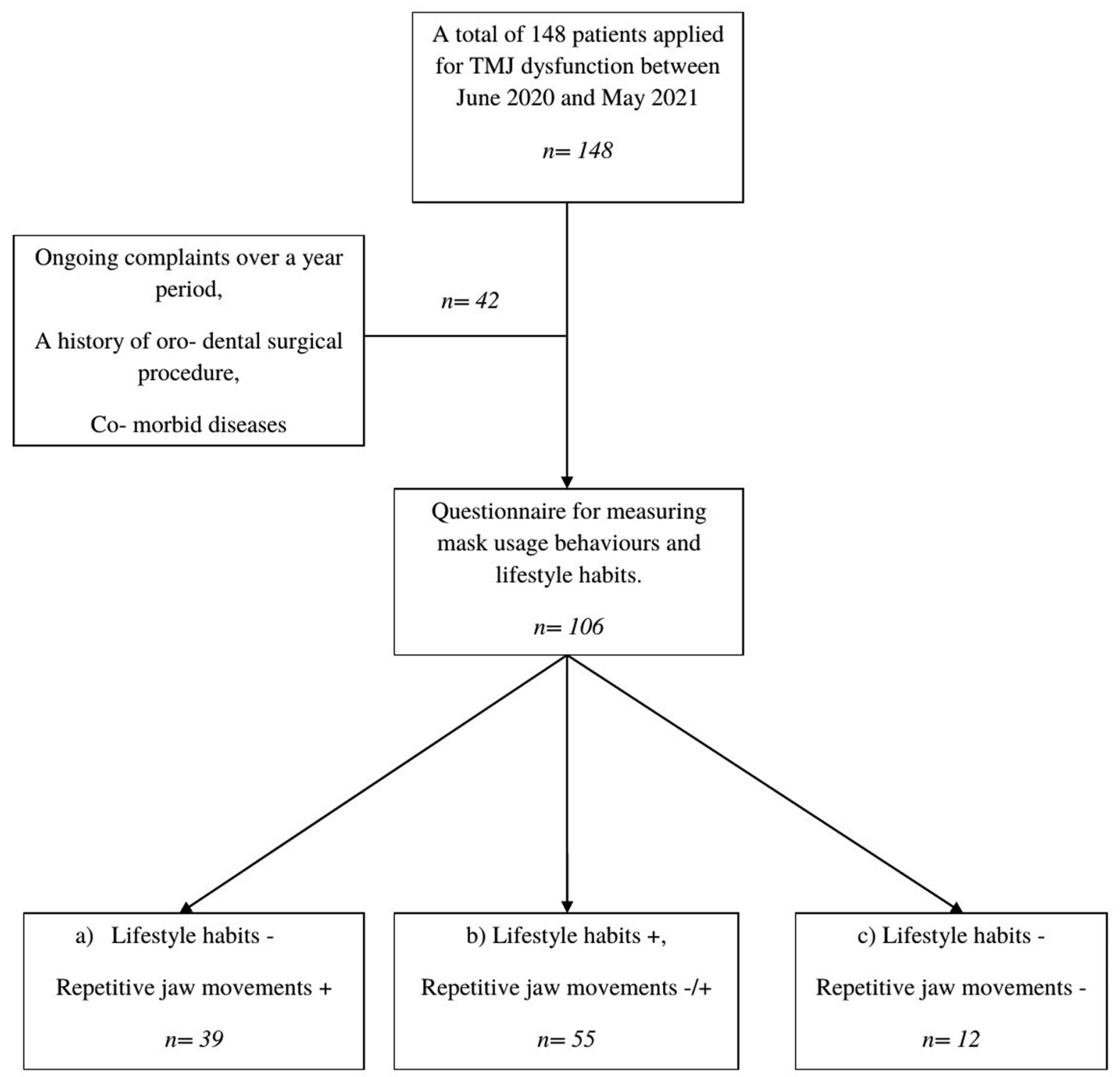

Fig. 2 Design of the study and patient screening. TMJ, temporomandibular joint.

moderate usage (3-8 hours/day) was most common. There was no significant difference between the groups in terms of mask type (-Table $\mathbf{1}$ ).

Pain was the main reported complaint in group a; however, the rates of stiffness and joint lock in this group were significantly lower than those of group b and c (-Table 2). The pain was found to be significantly low in the patients with no etiological factor (group $c)(p<0.001)$, while the other complaints were mostly encountered in this group.

Four basic radiological signs were observed in MRI (-Fig. 4). Abnormal morphologic features in TMJ disk were the main findings in all groups. Thickening of the lateral pterygoid muscle attachment was the most frequently encountered finding among the internal derangement pathologies. Disk displacement with reduction (DDWR) was significantly higher in patients with mask-related repetitive jaw movements $(p=0.010)$ ( - Table 3 ). There was no posterior disk displacement in any of the MRI. Osteoarthritis was detected in 8.9 and $32.3 \%$ of patients in group a and group c, respectively.

\section{Discussion}

The etiology of TMD is multifactorial including initiating factors (trauma, parafunctional habits, etc.), predisposing factors (genetic, structural, and psychological determinants), and perpetuating factors (metabolic, muscle stress, etc.). ${ }^{21}$ The combination of biological, structural, and psychosocial factors contributes to the etiopathology of TMD. ${ }^{22-25}$ Biological factors represent the systemic influence of muscular and articular structures on TMD, while the psychosocial dimension investigates the effects of the psychological and environmental determinants on masticatory behaviors. Finally, the structural dimension carries out the local somatic components of the musculoskeletal system related to TMJ and occlusion. As a result of this study, we believe that mask- 
This is a questionnaire to know about your mask usage behaviours and lifestyle habits, and to determine the underlying mechanism of your temporomandibular joint disorder. Please feel free to give your honest response for the questions stated below. Your identity and responses will be kept confidential and will be used with your consent for research purpose only.

Age Gender

a) Mask usage behavior:

1. Do you need to tense or push your jaw down forward to hold your mask on?

Yes No

2. Is it obligatory to wear a mask at work?

Yes No

3. How many hours a day do you wear a mask? $\leq$ , 3-8 , $8 \leq$

4. Which type of mask do you usually prefer? Cloth mask Surgical mask Respirator mask (FFP or N95 masks)

b) Lifestyle habits:

1. Do you clench your teeth during the day?

2. Do you grind your teeth at night? (Ask someone)

3. Does chewing gum start up your symptoms?

4. Do you have a habit of nail biting?

5. Do you have a habit of lip biting?
Yes

Yes

Yes

Yes

Yes
No

No

No

No

No

Fig. 3 Patient screening questionnaire applied in the study.

related repetitive jaw movements should be considered as a psychosocial factor.

A vector of the jaw motion is bidirectional with its forward and downward components (- Fig. 1). The tension exposed to the articular ligaments plays a significant role in the stability of TMJ. ${ }^{26}$ These ligaments provide the functional continuity of TMJ by stabilizing it. Sphenomandibular ligament protects TMJ from excessive translation movements following mouth opening at $10^{\circ}$, stylomandibular ligament limits extensive protrusion of jaw, while collateral ligament serves to anchor the disk to the condyle. Strain of these structures likely results in either dislocation due to the laxity of the ligaments or inflammatory changes in disk morphology. One of the reasons of the maneuver applied by the patients to correct the face mask position matches up with the fact that these masks are produced in standard sizes, 
62 Temporomandibular Joint Dysfunction Induced by a Face Mask Zuhour et al.

Table 1 Demographic data and characteristic features of the patients

\begin{tabular}{|c|c|c|c|c|c|c|c|c|c|c|}
\hline & \multirow[t]{2}{*}{ Mean age } & \multirow[t]{2}{*}{$M: F$} & \multicolumn{3}{|c|}{$\begin{array}{l}\text { Duration of wearing mask } \\
(\%)\end{array}$} & \multicolumn{2}{|c|}{$\begin{array}{l}\text { Obligation of } \\
\text { wearing mask } \\
\text { at work (\%) }\end{array}$} & \multicolumn{3}{|c|}{ Type of mask (\%) } \\
\hline & & & $\leq 3(h / d)$ & $3-8(h / d)$ & $\geq 8(h / d)$ & Yes & No & $\begin{array}{l}\text { Cloth } \\
\text { mask }\end{array}$ & $\begin{array}{l}\text { Surgical } \\
\text { mask }\end{array}$ & $\begin{array}{l}\text { Respirator } \\
\text { mask }\end{array}$ \\
\hline Group a & $31.74 \pm 11.6$ & 11: 28 & 9.2 & 50.4 & 40.4 & 62.5 & 37.5 & 12.1 & 60.2 & 27.7 \\
\hline Group b & $34.20 \pm 9.8$ & 20: 35 & 30.1 & 46.5 & 23.4 & 53.2 & 46.8 & 28.6 & 52.7 & 18.7 \\
\hline Group c & $35.67 \pm 12.7$ & $8: 4$ & 35.8 & 48.9 & 15.3 & 48.9 & 51.1 & 18.2 & 49.8 & 32.0 \\
\hline$p$-Value & - & - & $0.028^{a}$ & 0.625 & $0.001^{a}$ & 0.313 & 0.260 & 0.190 & 0.231 & 0.143 \\
\hline
\end{tabular}

${ }^{a} p \leq 0.05$ was considered statistically significant.

Table 2 Complaints of the patients in the groups

\begin{tabular}{|l|l|l|l|l|}
\hline & $\begin{array}{l}\text { Group a } \\
(\%)\end{array}$ & $\begin{array}{l}\text { Group b } \\
(\%)\end{array}$ & $\begin{array}{l}\text { Group c } \\
(\%)\end{array}$ & -Value \\
\hline Pain & 86.9 & 89.0 & 44.2 & $<\mathbf{0 . 0 0 1 ^ { \mathrm { a } }}$ \\
\hline Articular noises & 82.1 & 71.6 & 91.1 & 0.121 \\
\hline Stiffness & 28.3 & 45.0 & 73.4 & $<\mathbf{0 . 0 0 1 ^ { \mathrm { a } }}$ \\
\hline Joint lock & 23.5 & 51.7 & 78.8 & $<\mathbf{0 . 0 0 1 ^ { \mathrm { a } }}$ \\
\hline Joint tension & 64.6 & 78.2 & 83.6 & 0.118 \\
\hline
\end{tabular}

${ }^{\mathrm{a}} p \leq 0.05$ was considered statistically significant.

Table 3 Temporomandibular magnetic resonance imaging findings of the patients

\begin{tabular}{|c|c|c|c|c|}
\hline & $\begin{array}{l}\text { Group a } \\
\text { (\%) }\end{array}$ & $\begin{array}{l}\text { Group b } \\
\text { (\%) }\end{array}$ & $\begin{array}{l}\text { Group c } \\
\text { (\%) }\end{array}$ & $p$-Value \\
\hline Abnormal disk morphologic features & 73.1 & 62.0 & 79.7 & 0.244 \\
\hline $\begin{array}{l}\text { Disk displacement in closed-mouth position and } \\
\text { disk displacement with reduction in open-mouth position }\end{array}$ & 54.6 & 33.3 & 30.4 & $0.010^{a}$ \\
\hline $\begin{array}{l}\text { Disk displacement in closed-mouth position and } \\
\text { disk displacement without reduction in open-mouth position }\end{array}$ & 17.2 & 28.1 & 29.9 & 0.430 \\
\hline Osteoarthritic changes & 8.9 & 15.7 & 32.3 & $0.029^{a}$ \\
\hline
\end{tabular}

${ }^{a} p \leq 0.05$ was considered statistically significant.

while face shapes of the patients are unique. Patients try to hold their masks in the appropriate position by repetitive jaw movements as the masks are either loose or tight. Moreover, to obtain this position, patients use their maximum capacity of mandible protrusion and rotation at every turn. Maximum protrusion of the mandible has been shown to activate mechanical nociceptors, ${ }^{27}$ and this explains for high rates of pain in group a patients. For the other symptoms (articular noises and joint tension) which were not statistically different between groups, we consider this as a significant sign since the lifestyle habits like chewing gum and clenching teeth (group b) had already been shown to be associated with TMD, ${ }^{6-9}$ which means that fixing the position of a face mask using the jaw is at least associated with TMD as much as these lifestyle habits are.

It is also important to mention that some patients do not prefer to fix their masks manually to avoid infection spread, while others are not able to use their hands at work. There was a significant association between the duration of mask usage and repetitive jaw movements in group a (-Fig. 5); thus, prolonged mask usage can induce TMD in patients who tend to fix their masks by using their jaws.

In accordance with previous studies, most of the patients in our study were females. ${ }^{28,29}$ Although both males and females are affected by TMD in the same proportion, the ratio of females to males with severe TMD signs is $8: 1 .^{28}$ This is related to biological, anatomical, or hormonal factors acting alone or in combination in females. ${ }^{30,31}$ Additionally, in a study by Bagis et al, females with TMD showed a higher antidepressant usage rate compared with male patients. ${ }^{32}$

The most common radiological finding of TMD is internal derangement due to abnormal relationship between TMJ disk and condyle. Precise localization of the articular disk is crucial for the diagnosis of internal derangement in TMD and can be easily detected by MRI. Previous studies demonstrated anterior disk displacement in 30 to $34 \%$ of asymptomatic volunteers, 

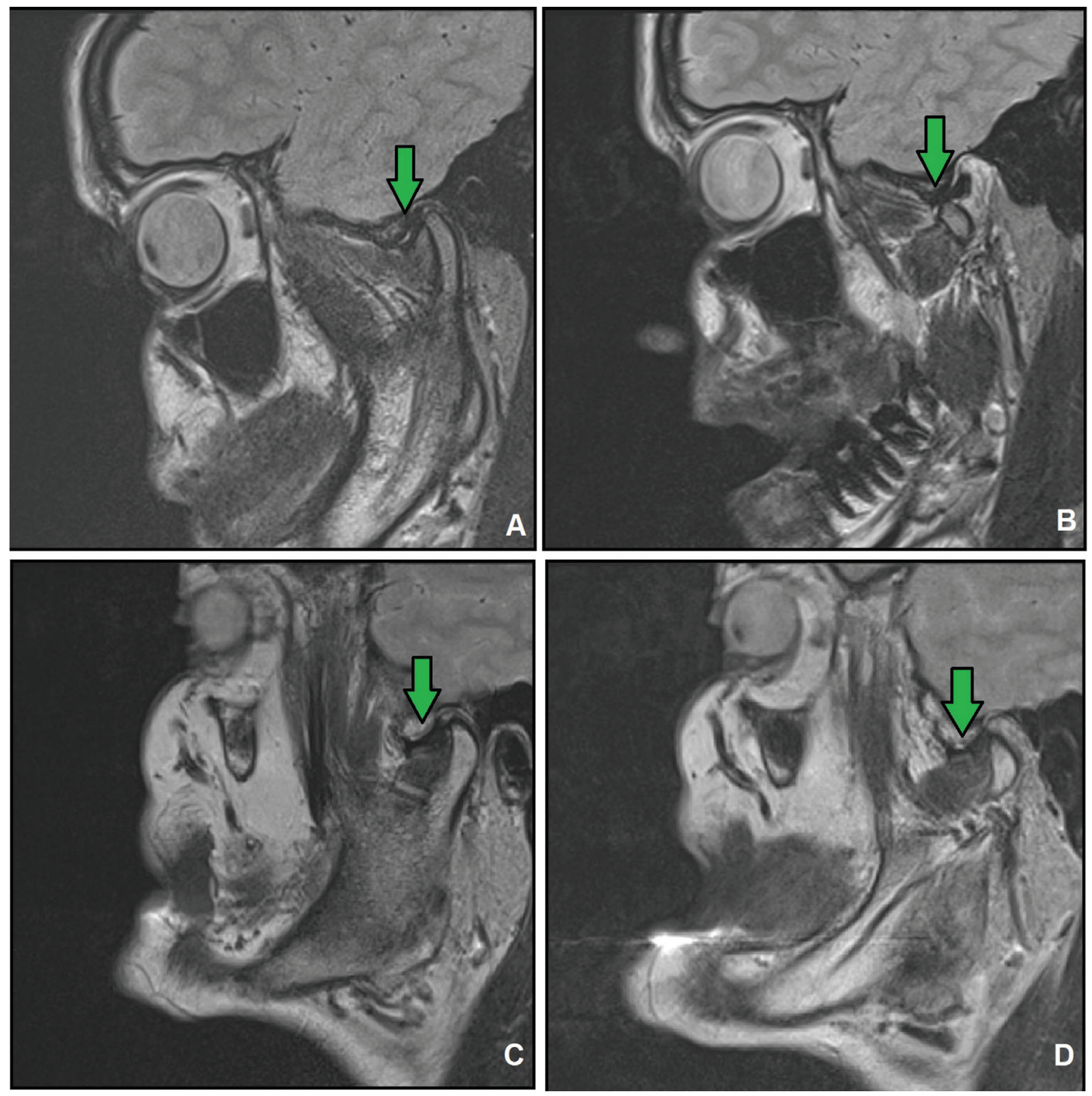

Fig. 4 Temporomandibular MRI findings. (A) Disk displacement in closed-mouth position and (B) disk displacement with reduction in open-mouth position. (C) Disk displacement in closed-mouth position and (D) disk displacement without reduction in open-mouth position (green arrow indicates temporomandibular disk). MRI, magnetic resonance imaging.

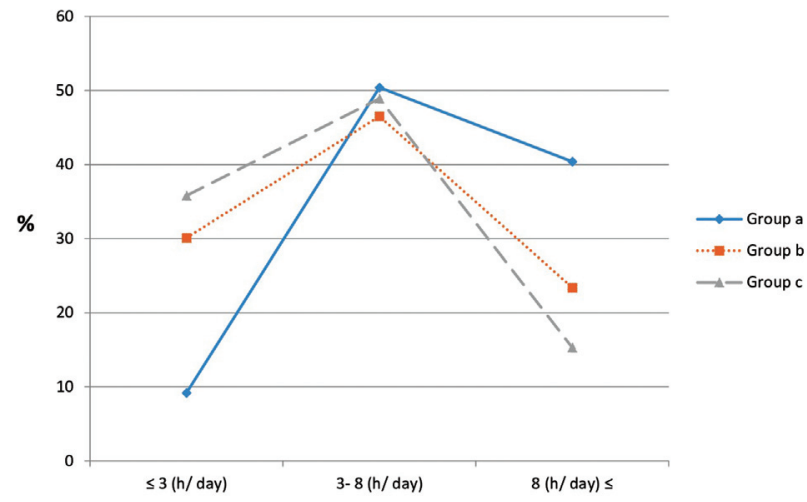

Fig. 5 Distribution of patients by the duration of mask usage. while normal disk position was reported in 13 to $23 \%$ of symptomatic patients. ${ }^{33,34}$ In our study, four radiological signs were detected including abnormal morphologic features of the disk, disk displacement in closed-mouth position, disk displacement with/without reduction in open-mouth position, and osteoarthritic changes (-Table 3 ). Changes in the morphologic features of TMJ disk were the main finding in all groups. Disk flattening, irregular, and rounded morphologic features are diagnostic for TMD. ${ }^{35}$ In early stages, disk maintains its normal shape despite stress. However, displaced disk results in the thickening of posterior band and reduction in the mass of anterior band over time. ${ }^{35}$

To investigate the effect of jaw movements on TMJ, patients with TMD signs in the recent year were only included in our study; thus, early morphologic changes 
were the most common pathology detected in MRI. Group a had a significantly higher rate of DDWR. This can be explained by the fact that patients use their maximum capacity of mouth opening at every turn to hold their mask in the right position, which leads to joint instability as reported previously by Maruyama et al. ${ }^{36}$ Surprisingly, osteoarthritis was significantly higher in patients with no underlying risk factor (group c) though the complaints of TMD were encountered in the recent year. Systemic disorders such as autoimmune diseases can cause joint problems and further examinations and interventions should be considered in this population. ${ }^{37,38}$

The lack of standardized mask sizes is one of the main limitations of our study. Several types of masks with variable strength, elasticity, covering capacity, etc., are produced by different companies; homogeneous sampling in terms of producing company did not seem probable. Moreover, three major types of the mask were specified in the study; however, there are also several subgroups for each of these types, for example, surgical masks can be used either by hanging off its' elastic strings behind the ears or by tying its' ropes around the head. The short term of our study is another limitation. Our preliminary study demonstrates the unfavorable effects of mask-related repetitive jaw movements on TMJ; thus, further studies are required to address long-term results and radiological findings. Additionally, duration and obligation of wearing masks were the parameters assessed in this study, while occupation-based studies will also be worthwhile.

\section{Conclusions}

In addition to the rarely reported face mask-related health problems, this study revealed the correlation between maskrelated repetitive jaw movements and TMD. Patients with prolonged daily mask usage ( $>8$ hours/day) are under a higher risk of TMD. Creating awareness in the population about this habit and the importance of choosing the appropriate mask is an important issue and should be taken into consideration while encouraging people to wear their masks. In accordance with the literature, female patients are more prone to mask-related TMD than male patients. As a result of this study, we recommend that mask-related habits should be among routinely questioned lifestyle habits, especially in patients applying with TMD complaints during pandemics.

\section{Funding}

None.

\section{Conflict of Interest}

We (all of the authors) have agreed to allow full access to the primary data and to allow the journal to review the data if requested. None of the authors has a financial interest in any of the products, devices, or drugs mentioned in this manuscript.

\footnotetext{
Acknowledgment

We (all authors) thank Wafaa Zuhour and Anas Zuhour for the creation of illustrations.
}

\section{References}

1 Graber TM, Rakosi T, Petrovic AG. Dentofacial orthopedics with functional appliances. In: Functional Analysis-Examination of Temporomandibular Joint and Condylar Movement. 2nd ed. St. Louis, MO: Mosby; 2009:135-140

2 Choi YS, Choung PH, Moon HS, Kim SG. Temporomandibular disorders in 19-year-old Korean men. J Oral Maxillofac Surg 2002;60(07):797-803

3 Chisnoiu AM, Picos AM, Popa S, et al. Factors involved in the etiology of temporomandibular disorders-a literature review. Clujul Med 2015;88(04):473-478

4 Gesch D, Bernhardt O, Mack F, John U, Kocher T, Alte D. Association of malocclusion and functional occlusion with subjective symptoms of TMD in adults: results of the Study of Health in Pomerania (SHIP). Angle Orthod 2005;75(02):183-190

5 Manfredini $D$, Segù $M$, Arveda $N$, et al. Temporomandibular joint disorders in patients with different facial morphology. A systematic review of the literature. J Oral Maxillofac Surg 2016;74(01):29-46

6 Gavish A, Halachmi M, Winocur E, Gazit E. Oral habits and their association with signs and symptoms of temporomandibular disorders in adolescent girls. J Oral Rehabil 2000;27(01):22-32

7 Sari S, Sonmez H. Investigation of the relationship between oral parafunctions and temporomandibular joint dysfunction in Turkish children with mixed and permanent dentition. J Oral Rehabil 2002;29(01):108-112

8 Winocur E, Littner D, Adams I, Gavish A. Oral habits and their association with signs and symptoms of temporomandibular disorders in adolescents: a gender comparison. Oral Surg Oral Med Oral Pathol Oral Radiol Endod 2006;102(04):482-487

9 Schiffman EL, Fricton JR, Haley D. The relationship of occlusion, parafunctional habits and recent life events to mandibular dysfunction in a non-patient population.J Oral Rehabil 1992;19(03):201-223

10 Coronaviridae Study Group of the International Committee on Taxonomy of Viruses. The species Severe acute respiratory syndrome-related coronavirus: classifying 2019-nCoV and naming it SARS-CoV-2. Nat Microbiol 2020;5(04):536-544

11 Dorfman D, Raz M. Mask exemptions during the COVID-19 pandemic-a new frontier for clinicians. JAMA Health Forum 2020;1(07):e200810-e200813

$12 \mathrm{Kim}$ MN. What type of face mask is appropriate for everyonemask-wearing policy amidst COVID-19 pandemic? J Korean Med Sci 2020;35(20):e186

13 Han C, Shi J, Chen Y, Zhang Z. Increased flare of acne caused by longtime mask wearing during COVID-19 pandemic among general population. Dermatol Ther (Heidelb) 2020;33(04):e13704

14 Szepietowski JC, Matusiak Ł, Szepietowska M, Krajewski PK, Białynicki-Birula R. Face mask-induced itch: a self-questionnaire study of 2,315 responders during the COVID-19 pandemic. Acta Derm Venereol 2020;100(10):adv00152

15 Asadi-Pooya AA, Cross JH. Is wearing a face mask safe for people with epilepsy? Acta Neurol Scand 2020;142(04):314-316

16 Li Q, Tarimo CS, Miao Y, Zeng X, Wu C, Wu J. Effects of mask wearing on anxiety of teachers affected by COVID-19: a large cross-sectional study in China. J Affect Disord 2021;281:574-580

17 Boccardo L. Self-reported symptoms of mask-associated dry eye: a survey study of 3,605 people. Cont Lens Anterior Eye 2021: 101408

18 Hadayer A, Zahavi A, Livny E, et al. Patients wearing face masks during intravitreal injections may be at a higher risk of endophthalmitis. Retina 2020;40(09):1651-1656

19 Motta LJ, Guedes CC, De Santis TO, Fernandes KP, Mesquita-Ferrari RA, Bussadori SK. Association between parafunctional habits and signs and symptoms of temporomandibular dysfunction among adolescents. Oral Health Prev Dent 2013;11(01):3-7

20 Motghare V, Kumar J, Kamate S, et al. Association between harmful oral habits and sign and symptoms of temporomandibular joint disorders among adolescents. J Clin Diagn Res 2015;9 (08):ZC45-ZC48 
21 Venkateswaran S, Saravanakumar A, Divya Y. Diagnosis and management of temporomandibular joint disorders- what the medical and dental practitioners should know? Chettinad Health City Medical Journal. 2013;2(02):52-59

22 John MT, Dworkin SF, Mancl LA. Reliability of clinical temporomandibular disorder diagnoses. Pain 2005;118(1-2):61-69

23 List T, Axelsson S. Management of TMD: evidence from systematic reviews and meta-analyses. J Oral Rehabil 2010;37(06):430-451

24 Bouloux GF. Use of opioids in long-term management of temporomandibular joint dysfunction. J Oral Maxillofac Surg 2011;69 (07):1885-1891

25 Manfredini D, Bucci MB, Montagna F, Guarda-Nardini L. Temporomandibular disorders assessment: medicolegal considerations in the evidence-based era. J Oral Rehabil 2011;38(02):101-119

26 Cuccia AM, Caradonna C, Caradonna D. Manual therapy of the mandibular accessory ligaments for the management of temporomandibular joint disorders. J Am Osteopath Assoc 2011;111 (02):102-112

27 Cairns BE. Nociceptors in the orofacial region (temporo-mandibular joint and masseter muscle). In: Schmidt RF, Willis WD, eds. Encyclopedic Reference of Pain. Heidelberg, Germany: SpringerVerlag; 2006:14

28 Sharma S, Gupta DS, Pal US, Jurel SK. Etiological factors of temporomandibular joint disorders. Natl J Maxillofac Surg 2011;2(02):116-119

29 Poveda Roda R, Bagan JV, Díaz Fernández JM, Hernández Bazán S, Jiménez Soriano Y. Review of temporomandibular joint pathology. Part I: classification, epidemiology and risk factors. Med Oral Patol Oral Cir Bucal 2007;12(04):E292-E298

30 Mohlin B, Axelsson S, Paulin G, et al. TMD in relation to malocclusion and orthodontic treatment. Angle Orthod 2007;77(03):542-548
31 Bagis B, Ayaz EA, Turgut S, Durkan R, Özcan M. Gender difference in prevalence of signs and symptoms of temporomandibular joint disorders: a retrospective study on 243 consecutive patients. Int J Med Sci 2012;9(07):539-544

32 Lin SL, Wu SL, Huang HT, Lung FW, Chi TC, Yang JW. Can a 10minute questionnaire identify significant psychological issues in patients with temporomandibular joint disease? J Oral Maxillofac Surg 2017;75(09):1856-1865

33 Takahara N, Nakagawa S, Sumikura K, Kabasawa Y, Sakamoto I, Harada H. Association of temporomandibular joint pain according to magnetic resonance imaging findings in temporomandibular disorder patients. J Oral Maxillofac Surg 2017;75(09): 1848-1855

34 Katzberg RW, Westesson PL, Tallents RH, Drake CM. Anatomic disorders of the temporomandibular joint disc in asymptomatic subjects. J Oral Maxillofac Surg 1996;54(02):147-153, discussion 153-155

35 Tomas X, Pomes J, Berenguer J, et al. MR imaging of temporomandibular joint dysfunction: a pictorial review. Radiographics 2006; 26(03):765-781

36 Maruyama T, Kotani M, Ozaki H, Sumida N, Akanishi M, Kuroda T. A study on the condylar position of temporomandibular joint in the dysfunction of the stomatognathic system using tomography. J Osaka Univ Dent Sch 1984;24:89-96

37 Kobayashi R, Utsunomiya T, Yamamoto H, Nagura H. Ankylosis of the temporomandibular joint caused by rheumatoid arthritis: a pathological study and review. J Oral Sci 2001;43(02):97-101

38 Ramos-Remus C, Major P, Gomez-Vargas A, et al. Temporomandibular joint osseous morphology in a consecutive sample of ankylosing spondylitis patients. Ann Rheum Dis 1997;56(02): 103-107 